\title{
Global research trends in coronavirus disease 2019
}

\author{
Thai Thanh $\operatorname{Tran}^{1}$, Thanh Luu Pham ${ }^{1,2, *}$
}

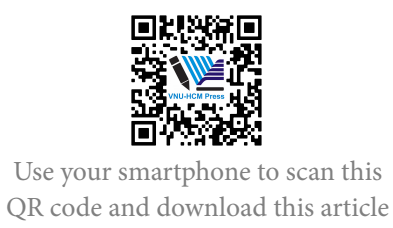

${ }^{1}$ Institute of Tropical Biology, Vietnam Academy of Science and Technology 85 Tran Quoc Toan Str., District 3, Ho Chi Minh City, Vietnam

${ }^{2}$ Graduate University of Science and Technology, Vietnam Academy of Science and Technology, 18 Hoang Quoc Viet Str., Cau Giay District, Ha Noi, Vietnam

\section{Correspondence}

Thanh Luu Pham, Institute of Tropical Biology, Vietnam Academy of Science and Technology 85 Tran Quoc Toan Str., District 3, Ho Chi Minh City, Vietnam

Graduate University of Science and Technology, Vietnam Academy of Science and Technology, 18 Hoang Quoc Viet Str., Cau Giay District, Ha Noi, Vietnam

Email: thanhluupham@gmail.com

\section{History}

- Received: 2020-08-11

- Accepted: 2020-10-06

- Published: 2020-10-10

DOI : $10.32508 /$ stdj.v23i4.2432

\section{Check for updates}

\section{Copyright}

(๑) VNU-HCM Press. This is an openaccess article distributed under the terms of the Creative Commons Attribution 4.0 International license.

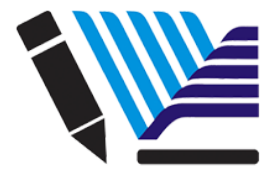

VNU-HCM Press

\begin{abstract}
Introduction: The outbreak of the novel coronavirus disease 2019 (COVID-19) is an ongoing global epidemic incident. The present study aims to bibliometrically analyze the global research trends of scientific papers related to COVID-19 with regard to the number of publications, subject categories, and prolific countries. A total of 47,061 publications, published during the last seven months, were collected and analyzed in this study. Methods: The bibliometric data in this study, which was extracted from the LitCovid Hub from January 17 to July 31, 2020. Results: Our results indicate that the number of publications on COVID-19 has increased significantly from January to July 2020, along with the rapid spread of the infection. China has produced the largest number of research papers on COVID-19 (5,751 articles, accounting for 12.2\%), followed by the USA (2,005 publications, accounting for $4.3 \%$ ) and Italy (1,374 publications, accounting for 2.9\%). Most recent research papers have focused on prevention, treatment, and diagnosis. Our results reveal that although the most affected countries are the USA, Brazil, India, and many countries in Europe, their contribution to research about COVID-19 has been limited. Conclusion: More research in the field of prevention, diagnosis, and treatment from highly affected countries is recommended. Overall, this study not only provides a global status update on COVID-19 scientific literature but also contributes to future research.
\end{abstract}

Key words: SARS-CoV-2, bibliometric study, epidemic, trend

\section{INTRODUCTION}

The outbreak of the novel coronavirus disease 2019 (COVID-19) with human to human transmission, having originated in Wuhan, China in early December 2019, is an ongoing global epidemic incident $^{1,2}$. By March 2020, the World Health Organization (WHO) declared it as a pandemic due to the rapid global spread and transmission ${ }^{3}$. COVID-19 is truly a global crisis with more than 210 countries, areas, or territories affected, a total number of confirmed cases surpassing 17.6 million, and the number of total deaths exceeding 680,000 as of August $2,2020^{3,4}$. COVID-19 causes a cluster of symptoms that include severe respiratory illness and common flu signs, such as fever, cough, myalgia or fatigue, sputum production, headache, and diarrhea ${ }^{1}$. In more severe cases, the infection may lead to pneumonia, acute respiratory distress syndrome, kidney failure, and even death ${ }^{2,5}$.

Due to the speed of outbreak, transmission, and deadliness, COVID-19 has become a hot topic and has attracted significant research attention worldwide. The number of publications on the topic has increased dramatically during the last seven months. Bibliometric methods have been used to assess the trend in the research activity of publications ${ }^{6-9}$. These methods have been widely used for providing quantitative analyses on many infectious diseases, such as Ebola, John Cunningham virus, Zika virus, Mayaro fever, yellow fever, and Middle East respiratory syndrome coronavirus ${ }^{7}$. Research productivity regarding COVID19, however, has not been reported to date. This study aims to bibliometrically analyze global research trends of publications related to COVID-19 available on LitCovid Hub. The results of this study will provide a holistic picture of COVID-19-related research and allow scientists to establish future research directions.

\section{MATERIALS AND METHODS}

The LitCovid Hub (available at https://www.ncbi.n lm.nih.gov/research/coronavirus/), provided by the NLM/NCBI BioNLP Research Group, was used to select a representative set of publications related to this study ${ }^{10}$. The hub is updated daily with newly published articles and includes the most comprehensive database of international research articles related to COVID-19 in PubMed. LitCovid Hub has a more sophisticated search function than the available collection and identifies more $35 \%$ relevant articles through keyword-based searches for terms such as COVID-19, nCOV, 2019-nCoV, and other related search terms ${ }^{11}$. The total number of articles in LitCovid Hub is more 
than that of Scopus and Web of Science in the same period $^{11}$.

Moreover, the articles on the hub are further categorized by different research topics, including general information (general information and news), the mechanism (symptoms, clinical characteristics, and findings from sequence and image analysis), transmission (characteristics and modes of COVID-19 transmissions, such as human-to-human), diagnosis (disease assessment through symptoms, test results, and radiological features), treatment (treatment strategies, therapeutic procedures, and vaccine development), prevention (prevention, control, and management strategies), case report (descriptions of specific patient cases), and epidemic forecasting (modeling and estimating the trend of COVID-19 spread) ${ }^{10}$. We analyzed publication activity concerning COVID19 in LitCovid hub from January 17 to July 31, 2020. Based on a search conducted on July 31, 2020.

\section{RESULTS - DISCUSSION}

\section{Cumulative number of articles}

Research on COVID-19 has increased significantly during the last seven months. The first article appeared on January 17, 2020, in the Journal of Travel Medicine. Since then, over 47,000 scientific papers have been published in different academic journals. The total number of articles published each month has increased sharply from 55 articles in January 2020 to 686 articles in February 2020, 1,945 articles in March 2020, 6,645 articles in April, 9,784 articles in May, 18,749 in June, and 9,197 articles in July 2020. The results reveal an overall increasing trend in the total number of scientific publications on COVID-19 during the last seven months (Figure 1 a).

This study sheds light on the development of scientific reporting regarding COVID-19 over the last seven months. The worldwide cumulative number of publications multiplied by ten after just one month (from January to February 2020), and it continues to increase each month sharply. The bibliometric analysis shows that an increasing number of articles pertaining to COVID-19 were published. This steep increase reflects the robust scientific response worldwide to the outbreak of the virus and may be attributed to the increase in the awareness of COVID-19 ${ }^{12,13}$.

\section{Publication distribution of subject cate- gories}

COVID-19 articles from around the world were separated into eight subject categories as shown in Figure $1 \mathrm{~b}$. Of the categories, prevention was in the lead $(49.6 \%)$, followed by treatment (17.7\%), diagnosis $(11.8 \%)$, mechanism $(8.5 \%)$, case reports $(5.3 \%)$, general information $(3.3 \%)$, transmission $(2.6 \%)$, and forecasting (1.0\%).

Figure 2 shows the global trend and distribution of COVID-19 published articles by the eight subject categories month wise. Although the total number of articles increased in all subject areas during the last seven months, the proportion of each subject category varied each month. In January 2020, the top three were general information (30.9\%), transmission (27.3\%), and mechanism (20.0\%), but in February 2020 , the top three subject categories changed to prevention $(21.4 \%)$, the mechanism $(18.4 \%)$ and treatment (18.1\%), and this order was preserved in March, but changed to prevention, treatment, and diagnosis in April 2020, especially the proportion of prevention has largely increased in April, and June 2020 (40.2\% and $68.4 \%$, respectively). The research trends in prevention and treatment increased significantly while the trends in mechanisms, transmission, general information, and forecasting decreased. The diagnosis category increased quite notably during January and February 2020, but a little decreased in March, and increased again in April and May 2020, then decreased in June. The case report category was non-existent in January 2020, but increased rapidly in February (6.1\%) and varied from $3.7 \%$ to $7.2 \%$ from March to July 2020.

Our results indicated that the global research trend has changed from general information and transmission to prevention, treatment, and diagnosis during the last seven months, along with a sharp increase in the number of infections and deaths.

\section{PUBLICATION DISTRIBUTION OF COUNTRIES OR TERRITORIES}

Most mentioned countries or territories in the abstract were showed in Table 1. Only countries from North America, Europe, and Asia have participated in COVID-19 research. Countries from South America and Africa have not contributed to the scientific research output on COVID-19. Table 1 lists the countries or territories with article output categorized by the eight subject categories. The top three productive countries are China, the USA, and Italy. The number of scientific publications was dominant in China, accounting for more than $10 \%$ of the total worldwide output (5,751 articles, accounting for 12.2\%), followed by the USA (2,005 publications, accounting for $4.3 \%)$, and Italy (1,374 publications, accounting for $2.9 \%)$. The UK came in fourth with 449 articles, accounting 


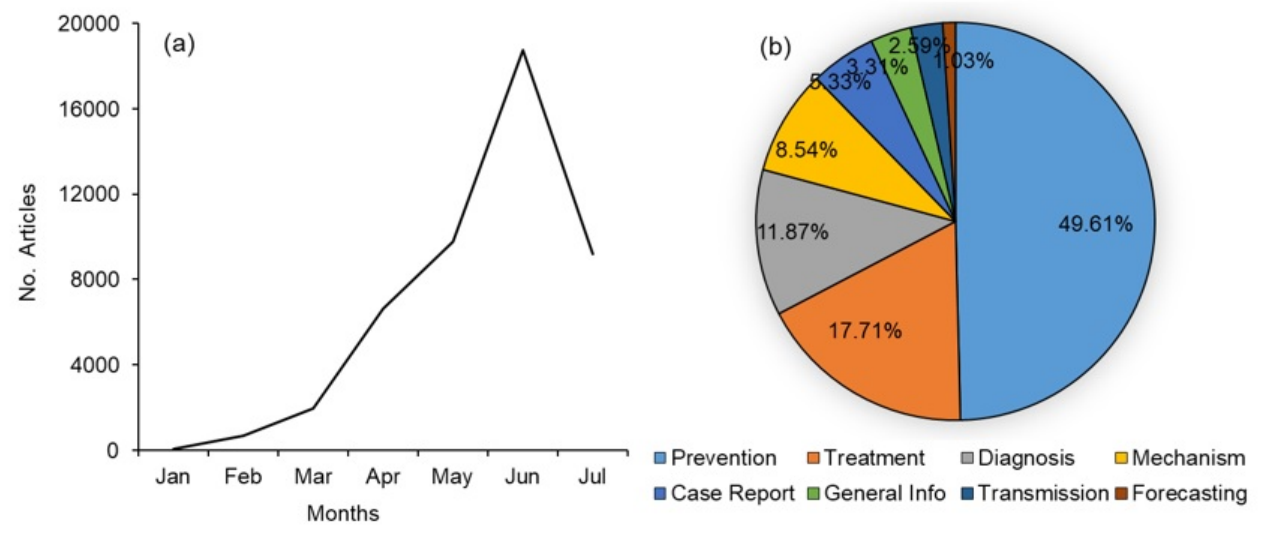

Figure 1: Cumulative number of COVID-19 articles published by Pubmed (a), and distribution of subject categories (b). Total articles: 47,061 .

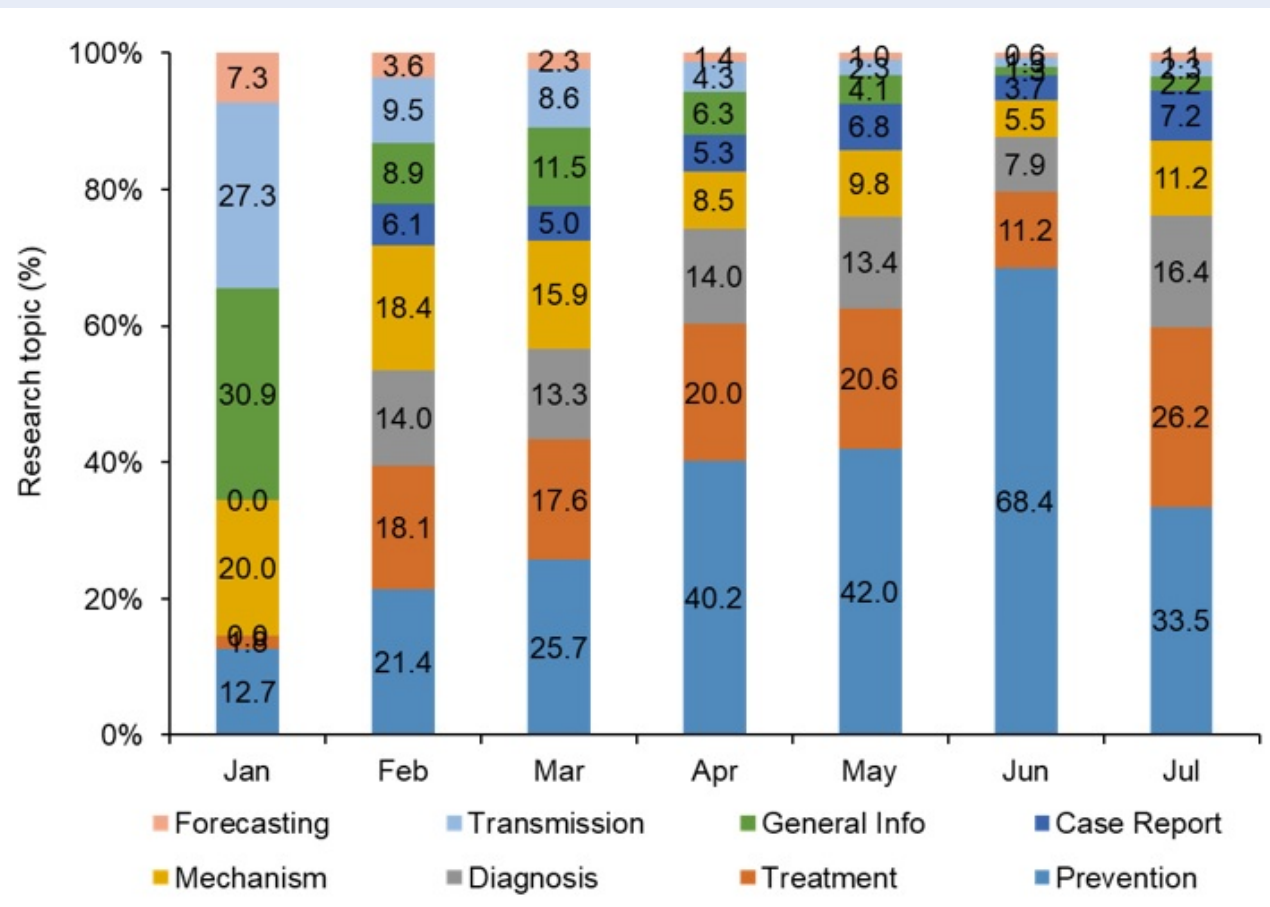

Figure 2: The global trend of COVID-19 published articles by the eight subject categories. 
for $1.0 \%$. Spain and France also contributed to this field with no less than 130 articles each. Contributions from other countries were considerably small. The distribution of articles per subject category was almost the same in the top three countries (China, the USA, and Italy). Most research dealt with the prevention, followed by treatment and diagnosis. In contrast, most articles from the UK focused on prevention and general information, while most articles from Spain and France concerned diagnosis and treatment.

Regarding the research production on COVID-19, China has ranked at the top with regard to the quality and quantity of published papers in all COVID-19 subject areas. It is possible that this is due to the fact that the first outbreak and subsequent increase in the prevalence of COVID-19 happened in China ${ }^{1,2,13}$. However, the most affected now are the USA, Brazil, and India, where the USA has recorded the world's highest number of deaths from COVID-19 with over 150,000 deaths ${ }^{14}$. In contrast, the relatively small research contribution of these countries compared to China is rather surprising. This is probably linked to the failure in the prevention of COVID-19 in these countries. Our results imply that the governments and researchers from the USA and other countries failed to act in a timely manner in the prevention of COVID-19. More research in the field of prevention, treatment, and diagnosis from highly affected countries is required.

Southeast Asian countries or the Association of Southeast Asian Nations (ASEAN), being one of the closest regions with China, have taken various measures to slow down and contain the spread of the pandemic virus. Extensive control and mitigation efforts have been taken by almost every country where the disease has been reported. Vietnam has been named in a shortlist of the top countries which has control well to the COVID-19 pandemic. Despite a long border with China and a population of 97 million people, Vietnam has successfully limited the spread of COVID-19 so far, only more than 1000 confirmed cases with only 35 deaths as of Sep 2020. The specific measures for successful prevention and control of COVID-19 in Vietnam have been discussed in detail. That included rapid response, clear leadership, supported clinical care and emergency public health response, multi-sectoral approach, and outstanding challenges ${ }^{15}$. These ongoing experience in reducing the spread of COVID-19 in Vietnam could provide useful learning for other countries.

There is currently no vaccine to prevent COVID-19. According to WHO (2020), there are currently over
169 COVID-19 vaccine candidates under development in the world, with many of these in the human trial phase. China has 11 vaccines in clinical trials, four in the human trial phase. The other four COVID19 vaccine candidates have also begun enrolling adult volunteers in the United States. When a safe and effective vaccine is found, the WHO will facilitate the equitable access and distribution of these vaccines to protect people in all countries. Most experts think vaccines for COVID-19 would become widely available by mid- $2021^{14}$.

\section{CONCLUSION}

Although bibliometric methods have been applied in several fields of infectious diseases, this is the first study on global research trends on COVID-19 using bibliometric analysis. Overall, our results reveal the global research products related to COVID-19. The total number of publications on COVID-19 has increased significantly since January 2020. The research trend on subject categories has been prevention, treatment, and diagnosis. China has produced the largest number of research papers on COVID-19, followed by the USA and Italy. Most recent research papers have focused on prevention, treatment, and diagnosis. More research from highly affected countries is highly recommended. In general, this study not only provides a status update on global COVID-19 research but also contributes to future research possibilities.

\section{LIST OF ABBREVIATIONS \\ COVID-19: Coronavirus disease 2019 \\ USA: United States of America \\ UK: United Kingdom \\ WHO: World Health Organization}

\section{COMPETING INTERESTS}

The authors declare that they have no conflicts of interest.

\section{AUTHORS' CONTRIBUTIONS}

Thai Thanh Tran and Thanh Luu Pham collected and statistical analysis the data, prepared the manuscript text. The final version of the manuscript was approved by all authors.

\section{REFERENCES}

1. Huang $C$, Wang $Y, L i X$, Ren L, Zhao J, Hu Y, Zhang L, Fan G, Xu J, Gu X, Cheng Z, YuT, Xia J, Wei Y, Wu W, Xie X, Yin W, Li H, Liu M, Xiao Y, Gao H, Guo L, Xie J, Wang G, Jiang R, Gao Z, Jin Q, Wang J, Cao B. Clinical features of patients infected with 2019 novel coronavirus in Wuhan, China. The Lancet. 2020;395(10223):497-506. Available from: https://doi.org/10. 1016/S0140-6736(20)30183-5. 
Table 1: The most mentioned countries in the abstract with the number of article output of 8 subject categories

\begin{tabular}{|c|c|c|c|c|c|c|c|c|}
\hline & $\begin{array}{l}\text { General } \\
\text { Info }\end{array}$ & Mechanism & Transmission & Diagnosis & Treatment & Prevention & $\begin{array}{l}\text { Case } \\
\text { Report }\end{array}$ & Forecasting \\
\hline United Kingdom & $\begin{array}{c}112 \\
(38.10)\end{array}$ & & $2(0.37)$ & & & $\begin{array}{c}335 \\
(8.06)\end{array}$ & & \\
\hline China & $79(26.87)$ & $\begin{array}{c}706 \\
(77.76)\end{array}$ & $\begin{array}{c}421 \\
(77.68)\end{array}$ & $\begin{array}{c}1125 \\
(65.26)\end{array}$ & $\begin{array}{c}1283 \\
(67.60)\end{array}$ & $\begin{array}{c}1681 \\
(40.44)\end{array}$ & $\begin{array}{c}280 \\
(61.14)\end{array}$ & $\begin{array}{c}176 \\
(49.72)\end{array}$ \\
\hline $\begin{array}{l}\text { United States of } \\
\text { America }\end{array}$ & $71(24.15)$ & $89(9.79)$ & $57(10.52)$ & $\begin{array}{c}265 \\
(15.37)\end{array}$ & $\begin{array}{c}285 \\
(15.02)\end{array}$ & $\begin{array}{c}1105 \\
(26.58)\end{array}$ & $\begin{array}{c}77 \\
(16.81)\end{array}$ & $\begin{array}{c}56 \\
(15.82)\end{array}$ \\
\hline Italy & $20(6.80)$ & $61(6.71)$ & $35(6.46)$ & $\begin{array}{c}181 \\
(10.50)\end{array}$ & $\begin{array}{c}180 \\
(9.48)\end{array}$ & $\begin{array}{c}784 \\
(188.86)\end{array}$ & $\begin{array}{c}49 \\
(10.07)\end{array}$ & $\begin{array}{c}64 \\
(18.08)\end{array}$ \\
\hline India & $12(4.08)$ & $26(2.86)$ & & & & $\begin{array}{c}252 \\
(6.06)\end{array}$ & & \\
\hline Japan & & $27(2.97)$ & & & & & $\begin{array}{c}31 \\
(6.77) \\
\end{array}$ & \\
\hline Republic of Korea & & & $27(4.98)$ & & & & & $\begin{array}{c}31 \\
(8.76)\end{array}$ \\
\hline Spain & & & & $\begin{array}{c}80 \\
(4.64)\end{array}$ & $\begin{array}{c}86 \\
(4.53)\end{array}$ & & $\begin{array}{c}21 \\
(4.59)\end{array}$ & \\
\hline France & & & & $\begin{array}{c}73 \\
(4.23)\end{array}$ & $\begin{array}{c}64 \\
(3.37)\end{array}$ & & & \\
\hline $\begin{array}{l}\text { Islamic Republic } \\
\text { of Iran }\end{array}$ & & & & & & & & $\begin{array}{c}27 \\
(7.63) \\
\end{array}$ \\
\hline Total & $294(100)$ & $909(100)$ & $542(100)$ & $\begin{array}{l}1724 \\
(100)\end{array}$ & $\begin{array}{l}1898 \\
(100)\end{array}$ & $\begin{array}{l}4157 \\
(100)\end{array}$ & $\begin{array}{c}458 \\
(100)\end{array}$ & $\begin{array}{c}354 \\
(100)\end{array}$ \\
\hline
\end{tabular}

2. Ogen Y. Assessing nitrogen dioxide (NO2) levels as a contributing factor to coronavirus (COVID-19) fatality. Science of the Total Environment. 2020;726:138605. PMID: 32302812. Available from: https://doi.org/10.1016/j.scitotenv. 2020.138605.

3. World Health Organization (WHO). Coronavirus disease 2019 (COVID-19) situation report - 195;Available from: https://www. who.int/docs/default-source/coronaviruse/situation-reports/ 20200802- covid-19-sitrep-195.pdf?sfvrsn=5e5da0c5_2.2020.

4. Mehta P, McAuley DF, Brown M, Sanchez E, Tattersall RS, Manson JJ. COVID-19: consider cytokine storm syndromes and immunosuppression. The Lancet. 2020;395(10229):1033-1034. Available from: https://doi.org/10.1016/S0140-6736(20)306280 .

5. Jiang F, Deng L, Zhang L, Cai Y, Cheung CW, Xia Z. Review of the clinical characteristics of coronavirus disease 2019 (COVID-19). Journal of General Internal Medicine. 2020;35(5):1545-1549. PMID: 32133578. Available from: https://doi.org/10.1007/s11606-020-05762-w.

6. Wang Y, Zhai X, Liu C, Wang N, Wang Y. Trends of triple negative breast cancer research (2007-2015): a bibliometric study. Medicine. 2016;95(46):e5427. PMID: 27861384. Available from: https://doi.org/10.1097/MD.0000000000005427.

7. Al-Jabi SW. Global research trends in West Nile virus from 1943 to 2016: a bibliometric analysis. Global Health. 2017;13(1):55. PMID: 28774315. Available from: https://doi.org/10.1186/ s12992-017-0284-y.

8. Sweileh WM. Global research trends of World Health Organization's top eight emerging pathogens. Global Health 2017;13(9). PMID: 28179007. Available from: https://doi.org/ 10.1186/s12992-017-0233-9.

9. Yang S, Sui J, Liu T, Wu W, Xu S, Yin L, Pu Y, Zhang X, Zhang Y, Shen B, Liang G. Trends on PM2.5 research, 1997-2016: a bibliometric study. Environmental Science and Pollution Research. 2018;25(13):12284-12298. PMID: 29623642. Available from: https://doi.org/10.1007/s11356-018-1723-x.

10. Chen $Q$, Allot $A$, Lu Z. Keep up with the latest coronavirus research. Nature. 2020;579(7798):193. PMID: 32157233. Available from: https://doi.org/10.1038/d41586-020-00694-1.

11. Arab-Zozani M, Hassanipour S. Features and limitations of LitCovid Hub for quick access to literature about COVID-19. Balkan Medical Journal. 2020;37(4):231-232. PMID: 32292015. Available from: https://doi.org/10.4274/balkanmedj.galenos. 2020.2020.4.67.

12. Harapan H, Itoh N, Yufika A, Winardi W, Keam S, Te H, Megawat D, Hayati Z, Wagner AL, Mudatsir M. Coronavirus disease 2019 (COVID-19): a literature review. Journal of Infection and Public Health. 2020;13(5):667-673. PMID: 32340833. Available from: https://doi.org/10.1016/j.jiph.2020.03.019.

13. Lake MA. What we know so far: COVID-19 current clinical knowledge and research. Journal of Clinical Medicine. 2020;20(2):124-127. PMID: 32139372. Available from: https: //doi.org/10.7861/clinmed.2019-coron.

14. WHO, 2020. Access day: 28/09/2020;Available from: https://www.who.int/emergencies/diseases/ novel-coronavirus-2019/covid-19-vaccines?gclid=

CjwKCAjw8MD7BRArEiwAGZsrBS4EZeoXRslKKeBiR86nzG8 CcxhNQTNDvdzP8RKM0QuHPN5YAABGuhoCBfsQAvD_ BwE.

15. Ha BT, Ngoc Quang L, Mirzoev T, Tai NT, Thai PQ, Dinh PC. 
Combating the COVID-19 Epidemic: Experiences from Vietnam. International Journal of Environmental Research and
Public Health. 2020;17(9):3125. PMID: 32365851. Available from: https://doi.org/10.3390/ijerph17093125. 